\title{
Effect of weather factors on population fluctuations of mustard aphid (Lipaphis erysimi Kaltenbach)using path co-efficient analysis
}

\author{
R.L. KALASARIYA* and K.D.PARMAR \\ AINP on Pesticide Residues, ICAR, Unit-9, Anand Agricultural University, Anand-388 110, Gujarat \\ *E-mail:drkdp28@gmail.com.
}

\begin{abstract}
An attempt has been made to quantify the effect of weather parameters and ladybird beetle on population fluctuation of aphid using path analysis of data collected during rabi 2012-13 and 2013-14 at Junagadh Agricultural University, Junagadh. The result revealed that the direct effect of minimum and maximum temperatures on aphid population was negative and low $(-0.4939$ and -0.2628 , respectively) while it was positive and moderate $(0.5443)$ by mean temperature. The direct effect of morning relative humidity was positive and very high (1.8615), while mean relative humidity exhibited negatively very high direct effect $(-3.3158)$ on aphid population. Residual value indicated that all these biotic and abiotic factors had a total combined effect of 86.01 per cent on population build-up of mustard aphid. It indicated that only 13.99 per cent effect was through other unknown factors existing in the ecosystem during both seasons.
\end{abstract}

Key words: Weather parameters, mustard aphid, correlation, path co-efficient analysis

Mustard is an important oilseed crop which constitutes as a major source of edible oil. Mustard, Brassica juncea (Linnaeus) Czern and Coss belongs to family cruciferae. Biotic and abiotic parameters play a vital role in population build-up of insect pest. Mustard aphid $L$. erysimi causes 35.4 to 73.3 per cent yield loss, 30.09 per cent seed weight loss and 2.75 per cent oil loss (Bakhetia and Sekhon, 1989, Singh and Premchand, 1995 and Sharma and Kashyap 1998). Correlation study helps in to provide either positive or negative association of pest population with biotic or abiotic factors (Tahkur and Rawat, 2014; Saxena et al. 2012; Dabhi et al. 2013). Combined as well as individual effect of biotic and abiotic parameters on population fluctuation of the pest can be measured through path coefficient analysis. It gives direct influence of particular parameter on pest population build-up as well as its indirect effect through other parameters.

In the present study the efforts has been made to study the direct and indirect effect of various biotic and abiotic parameters on population build-up of mustard aphid.

\section{MATERIALS AND METHODS}

Field experiment was conducted at College farm, Junagadh Agricultural University, Junagadh, Gujarat during rabi 2012-13 and 2013-14 to study the population dynamics of mustard aphid on mustard variety "Gujarat Mustard-3". The crop was raised after following the standard agronomic practices in large plot and it was divided into ten equal sectors $(2.0 \mathrm{~m} \times 2.0 \mathrm{~m})$ considering one sector as one repetition. The plots were kept free from insecticidal spray throughout the crop period.Five plants were randomly selected from each sector. Observations were recorded at weekly interval starting from the first week of sowing till the maturity of crop. Generally, it was observed that mustard aphids sit in an overlapping manner and hence, it was difficult to record aphid on numerical basis. Hence, aphid index was determined aphid population as per criteria described by Patel et al. (1995) (Tabel 1).

The average aphid index was worked out by using the following formula.

Average aphid index $=\frac{0 \mathrm{~N}+1 \mathrm{~N}+2 \mathrm{~N}+3 \mathrm{~N}+4 \mathrm{~N}+5 \mathrm{~N}}{\text { Total }}$ Total number of plants observed

Where,

$0,1,2,3,4,5$ are the aphid index.

$\mathrm{N}=$ Number of plant showing respective aphid index.

The observations on aphid index were recorded visually from five randomly plant from each plot. On the average aphid index was worked out by the above formula.

During the present investigation, the effect (direct as well as indirect) of ten different biotic and abiotic parameter i.e. maximum temperature $\left(\mathrm{X}_{1}\right)$, minimum temperature $\left(\mathrm{X}_{2}\right)$, 


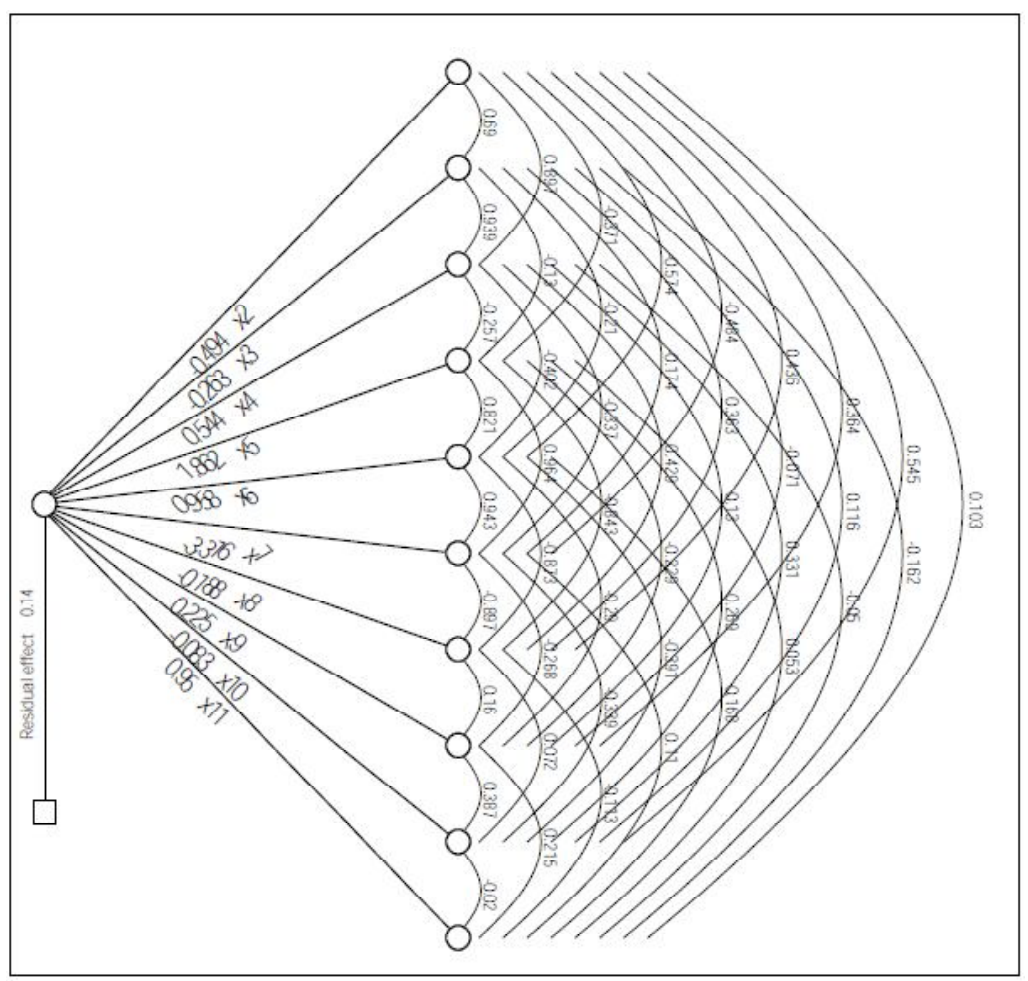

Fig. 1: Direct and indirect effect of key biotic and abiotic factors on population fluctuation of mustard aphid, L. erysimi during both seasons (Rabi 2012-13 \& 2013-14)

Table 1: Criteria for aphid index

\begin{tabular}{|c|c|}
\hline $\begin{array}{l}\text { Aphid } \\
\text { index }\end{array}$ & Criteria \\
\hline $\mathbf{0}$ & Plant free from aphid infestation. \\
\hline 1 & Only few aphids with very little injury. \\
\hline 2 & $\begin{array}{l}\text { Small colonies on few twigs, no curling or } \\
\text { yellowing of leaves. }\end{array}$ \\
\hline 3 & $\begin{array}{l}\text { Aphid colonies on almost all the twigs, stunted } \\
\text { growth, curling and yellowing of leaves. }\end{array}$ \\
\hline 4 & $\begin{array}{l}\text { Very heavy population of aphids on } \\
\text { inflorescence, leaves, stem and siliqua (pod) }\end{array}$ \\
\hline 5 & $\begin{array}{l}\text { Complete drying of plants due to heavy infestation } \\
\text { of aphids. }\end{array}$ \\
\hline
\end{tabular}

mean temperature $\left(\mathrm{X}_{3}\right)$, relative humidity percentage at morning $\left(\mathrm{X}_{4}\right)$, at evening $\left(\mathrm{X}_{5}\right)$, average relative humidity $\left(\mathrm{X}_{6}\right)$, sunshine hours $\left(\mathrm{X}_{7}\right)$, wind velocity $\left(\mathrm{X}_{8}\right)$, evaporation $\left(\mathrm{X}_{9}\right)$ and natural enemy $\left(\mathrm{X}_{10}\right)$ on the population build-up of mustard insect pests was studied with the help of path coefficient analysis. The statistical analysis was done according to the methods of Panse and Sukhatme (1985) for analysis of correlation co-efficient and NageswarRao (1983) for path co-efficient analysis.

\section{RESULTS AND DISCUSSION}

The data presented in Table 2 and depicted in Fig. 1 indicated that maximum temperature exhibited nonsignificant positive correlation $(r=0.2288)$ but it exerted negatively low direct effect $(-0.493)$ and minimum temperature having non-significant negative association $(\mathrm{r}$ $=-2080$ ) with aphid population also had a negatively low direct effect $(\mathrm{r}=-0.2628)$ on aphid population, indicating an unfavorable individual influence on the population buildup of aphid. Indirect effects of both these parameters were found to have negative low to moderate on aphid population through almost all other biotic and abiotic factors except mean relative humidity. The mean temperature was found to have non-significant negative correlation $(\mathrm{r}=-0.0178)$ but it exerted positively moderate direct effect $(0.5443)$, indicating a favorable individual influence on the population build-up of aphid. The indirect effect of this parameter was found negative low to low on aphid population through almost all the biotic and abiotic factors except mean relative humidity. The morning relative humidity exhibited nonsignificant negative correlation $(\mathrm{r}=-0.2897)$ but it exerted very high direct effect (1.8615) and evening relative humidity having non-significant negative association $(r=-$ 


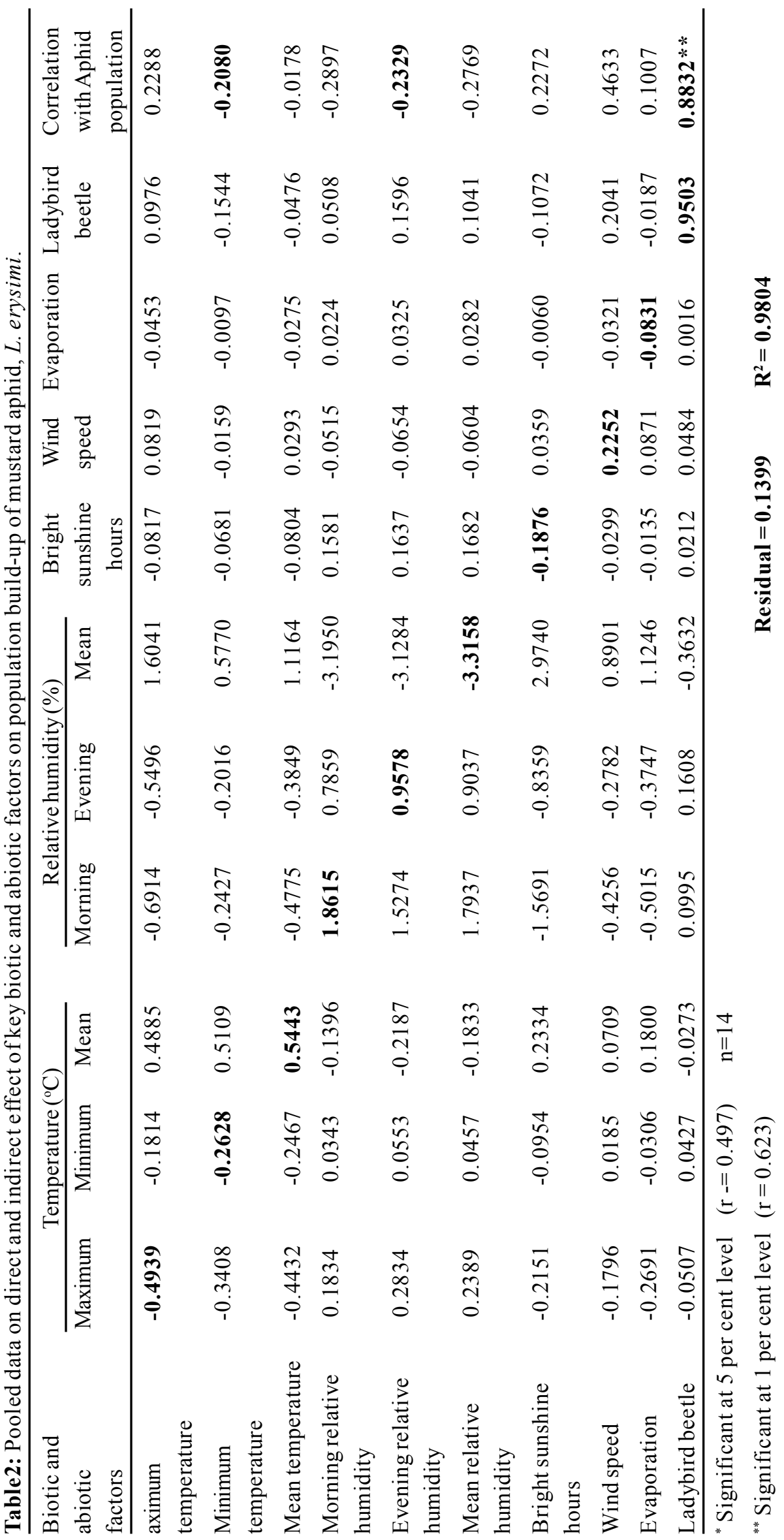


2329) with aphid population also had a moderate direct effect (0.9578) on aphid population, indicating an favorable individual influence on the population build-up of aphid. Indirect effects of both these parameters were also found to have negative low to moderate on aphid population through almost all other biotic and abiotic factors except morning and mean relative humidity. The mean relative humidity was found to be non-significant negative correlation $(\mathrm{r}=-0.2769)$ but it exerted negatively very high direct effect (-3.3158), indicating an unfavorable individual influence on the population build-up of aphid. The indirect effect of this parameter was found negative low to moderate on aphid population through almost all the biotic and abiotic factors except morning relative humidity.

The bright sunshine hours was found to have negativel low direct effect (-0.1876), indicating an unfavorable individual influence on the population buildup of aphid. This parameter exhibited negative low to negatively moderate indirect effects on aphid population through almost all the other biotic and abiotic factors except morning and mean relative humidity. The direct effect of wind speed was found to be positively low (0.2252), indicating a favorable individual influence on the population build-up of aphid. This parameter exhibited negatively low to low indirect effects on aphid population through almost all the other biotic and abiotic factors except mean relative humidity. The evaporation had a negative low direct effect $(-0.0831)$ on aphid population. This parameter exhibited negatively low to low indirect effects on aphid population through almost all the other biotic and abiotic factors except mean relative humidity. The population of ladybird beetle exhibited highly significant positive correlation $(\mathrm{r}=0.8832)$ but it exerted positively moderate direct effect $(0.9503)$ on population of aphid. This parameter exhibited negatively low to low indirect effects on aphid population through almost all the other biotic and abiotic factors.

Residual value presented (Table 2) indicated that all these biotic and abiotic factors had a total combined effect of 86.01 per cent on population build-up of mustard aphid. It indicated that only 13.99 per cent effect was through other unknown factors existing in the ecosystem.

\section{CONCLUSION}

Among all the weather factors, the mean relative humidity, bright sunshine hours and evaporationwere found to be negative and lowto very high direct effect on aphid population, indicating that increase in mean relative humidity, bright sunshine hours and evaporation would decrease the aphid population but positive very high direct effect of morning relative humidity on aphid population was found favorable for fast multiplication and dispersal of mustard aphid. The aphid population in mustard is affected greatly by different weather factors that fluctuate at various crop growth stages.

\section{REFERENCES}

Bakhetia, D.R.C. and Sekhon, B.S. (1989). Insect pests and their management rapeseed-mustard. J. Oilseeds Res., 6:269273.

Dabhi, M.V., Koshiya, D.J. and Korat, D.M. (2013). Effect of abiotic factors on population of aphid and damage by shoot and fruit borer in okra during summer and kharif season at Anand, Gujarat. J. Agrometeorol., 15(1): 7174.

Nagesar Rao, G. (1983). Statistics for agriculture sciences. Oxford and IBH publication. Co. New Delhi. pp. 376.

Panse, V.G. and Sukhatme, P.V.(1985). Statistical methods for agricultural workers. ICAR, New Delhi. pp. 381.

Patel, M.G., Patel, J.R. and P.K. Borad. (1995). Comparative efficacy and economics of various insecticides against aphid, Lipaphis erysimi(Kalt.) on mustard in Gujarat. Indian J. Plant Prot., 23: 217-218.

Saxena, S., Murty, N.S., and Singh, C.P. (2012). Effect of weather parameters on population dynamics of mustard aphid (Lipaphis erysimi Kalt.) in Tarai region of Uttarakhand. J. Agrometeorol., 14(2): 176-177.

Sharma, P.K. and Kashyap, N.P. (1998). Estimation of losses in three different oil seed Brassica crops due to aphid complex in Himachal Pradesh (India). J. Entomol. Res., 22: $22-25$.

Singh, P.K. and Premchand, (1995). Yield loss due to the mustard aphid Lipaphiserysimi(Kalt.) in Eastern Bihar Plateau. J. Applied Zool. Res., 6: 97-100.

Tahkur, M. and Rawat, S. (2014). Effect of abiotic factors on population dynamics of insect pests and natural ememies in potato crop. J. Agrometeorol., 16(2): 187-191. 